\title{
Anteckningar om Finska Heteroptera
}

\author{
af \\ O. M. Reuter. \\ (Anmäldt den 3 december 1899).
}

1. Neottiglossa pusilla Gmel. (inflexa Wolff) var. obscura J. Sahlb. I Notis. Skpts pro F. et Fl. Fenn. Förh. XI (1870) har pròf. J. Sahlberg uppstält en ny art af släktet Platysolen (= Neottiglossa) under benämningen obscurus, hvilken från den hos oss allmänna pusilla (= inflexa Wolff) skulle afvika icke blott genom mörkare färg och svart hufvud, men äfven genom saknaden af blek callus på hjässan och antennernas struktur. Jag eger emellertid äfven normalt färgade exemplar, hos hvilka hjässans punktur alldeles inkräktat på det callösa strecket. Antennernas andra och tredje leder variera i längd och förhålla sig hos typisk pusilla stundom alldeles så. som hos obscura. Slutligen är detsamma äfven• fallet med urbuktningen af hufvudets sidoränder framför ögonen, hvilken hos typexemplaren af obscurus (det ena från Ryska Karelen, det andra från Ryska Lappmarken) är starkare prononcerad än hos flertalet typiskt färgade individer af pusilla. Några andra hållbara karaktärer än den mörkare färgen finnas sålunda icke.

2. Pionosomus allœonotus n. sp. I Enum. Hemipt. Gymnoc. Fenn. upptager prof. Sahlberg Pionosomus varius Wolff på grund af ett exemplar, funnet af honom på den sandiga stranden af Konnevitz holme i Ladoga. Senare har emellertid d:r Horvath i Termeszetrajzi Füzetek XVIII, pars 2 (1895) publicerat en revision af detta släktes arter. Vid undersökning af vårt exemplar har jag kommit till det resultat att det icke 
tillhör någon af de 8 hittills kända, utan bildar ett nytt species, som isynnerhet genom sin mycket smalare och mer långsträckta prothorax lätt bör skiljas från $P$. varius, af hvilka jag eger ett exemplar från Sverige. På grund häraf har jag kallat vår art:

Pionosomus allœonotus n. sp. Corpore superne nigrosetoso, setis marginalibus pronoti diametro oculi paullo longioribus; antennis articulo primo et quarto fusco-nigris, secundo et tertio testaceis; pronoto (fig. 1) parum transverso (margine laterali latitudine basali solum circiter $1 / 4$ breviore), antrorsum levissime angustato, lateribus pone medium levissime, sed distincte sinuatis, lobo antico sat convexo, nigro-nitento, subtiliter sat vage punctato, lobo postico maculis duabus bene distinctis testaceis medio haud confluentibus; hemielytris ut in reliquis speciebus generis pictis; membrana nigro-fusca, gutta angulorum basalium guttisque quatuor apicalibus albis; femoribus nigris, solum posterioribus apice omnium angustissime obscure testaceis. Long. formae macropterae $2^{3} / 5 \mathrm{~mm}$. - A P. opacello Horv. lobo antico pronoti nitente pube griseo-albida destituto mox distinctus; a $P$. vario Wolff (fig. 2) statura minore structuraque pronoti (formae macropterae) parum transversa, a $P$. persimili Horv. pronoto lateribus distincte sinuato, maculis pallidis haud confluentibus, a $P$. trichoptero Thoms. pronoti setis lateralibus brevioribus loboque antico parcius punctato, a $P$. depresso Horv. pronoti marginibus lateralibus distincte sinuatis loboque antico convexo vage punctato nigronitente divergens.

Unicum specimen in insula Konnevitz lacus Ladoga die 6 juni 1875 invenit D. Prof. J. Sahl-

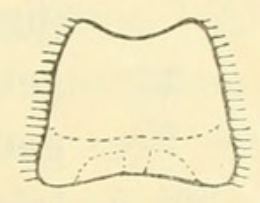

Fig. 1.

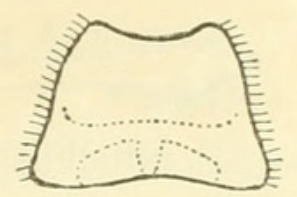

Fig. 2. berg.

(Obs. Den af mig i Hemipt. Heter. fr. Sajanska bärgskedjan (Öfv. Finska Vet. Soc. Förh. XXXIII, p. 182) anförda Pionosomus varius är $P$. monochrous Jak.).

3. Hydrometra gracilenta Horv. (= stagnorum J. Sahlb. nec Linné). I Termesz. Füzet. XXII (1899), p. 450 beskrifver 
Horvath från Ungern och Transcaucasien en ny Hydrometraart och uttrycker därvid den förmodan att äfven den af prof. Sahlberg såsom $H$. stagnorum L. från Finland i Not. Skpts pro F. et Fl. Fenn. Förh. XIV (1875) p. 268 beskrifna arten skulle med denna vara identisk. Med anledning häraf har jag undersökt alla i Universitetets Finska Museum förvarade exemplar (från Parikkala, Pulsa och Teisko, tagna af Sahlberg, samt från Österbotten, Wasastjerna) och funnit att dessa värkligen äro H. gracilenta Horv. De i Riksmuseum i Stockholm förvarade svenska exemplaren (alla från Skåne) höra däremot enligt benäget meddelande af prof. Chr. Aurivillus till $H$. stagnorum L.

De båda arterna afvika i följande hänseenden:

H. gracilenta Horv. (stagnorum J. Sahlb.): mindre och $\longrightarrow$ smalare, $71 / 2-9 \mathrm{~mm}$. lång, rostbrun $\left(\delta^{\prime}\right)$ eller

Fig. 3. rostgul (우), mer eller mindre svartbrokig; hufvudet (fig. 3) framför ögonen mindre än dubbelt så långt som bakom dessa; abdomens rygg glänsande; baklåren nående till sjätte (ठ) eller femte (우) abdominalsegmentets midt; hanens första genitalsegment Fig. 4. (fig. 4) från sidan sedt ofvantill horisontalt och utdraIf get i ett spetsigt utskott, som räcker ut öfver andra genitalsegmentet; honans öfre genitallamell (fig. 5) sedd

Fig. 5. från sidan ofvantill rak och i spetsen utdragen i ett horisontelt utskott.

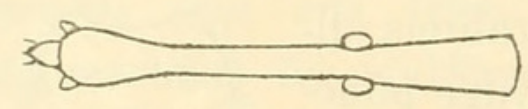

Fig. 6.

H. stagnorum L. nec Sahlb.: större och gröfre, 9-12 mm lång; nästan helt och hållet svart; hufvudet framför ögonen (fig. 6) dubbelt så långt som bakom dessa; abdo.

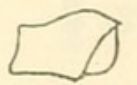

Fig. 7.

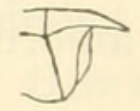

Fig. 8. mens rygg matt, fint gråpubescent; baklår nående till abdomens spets $\left(\sigma^{0}\right)$ eller midten af sjätte abdominalsegmentet (우); hanens första genitalsegment (fig. 7) från sidan sedt ofvantill konvext och helt kort utdraget, icke skjutande ut bakom andra segmentet; honans öfre genitallamell (fig. 8) från sidan sedd ofvantill konvex och i spetsen utdragen $\mathrm{i}$ ett lindrigt nedåtböjdt utskott. 
4. Acanthia (= Salda) marginalis Fall. nec. F. Sahlb. I Opuscula entomol. IV, pp. 405 och 406 beskrifver Thomson två närstående arter af detta släkte, af hvilka han kallar den ena marginalis Fall., den andra costalis F. Sahlb. Denna senare är i själfva värket identisk med marginalis F. Sahlb. nec Fall., under det costalis F. Sahlb. hör såsom synonym under opacula Zett. Den har därför af mig uppkallats med ett nytt namn, A. fennica (Ent. Tidskr. V, p. 171, 1884). Hos oss förekommer den i södra Finland ända upp till $61^{\circ}$ såväl vid hafskust på gyttjiga stränder, som vid träsk och på gungfly; för resten är den funnen endast i Livland. Den äkta marginalis Fall., som lätt skiljes genom i midten bredt svartbruna lår, gröfre i fläckar grupperad silfverpubescens, äfvensom därigenom att hemielytras gula sidorand i tredje spetsdelen är bredt afbruten af svart (nigro-interruptus), har hittills varit funnen endast i Sverige, Brittannien och Holland. Bland de i Universitetets museum förvarade af prof. J. Sahlberg i Nyland tagna hemiptera anträffade jag emellertid ett exemplar äfven af denna för vårt faunaområde nya art, funnet på en sphagnum-mosse i Sammatti d. 24 juli 1897.

5. Charagochilus Gyllenhali Fall. forma macroptera. Af denna ytterst sällsynta form, förut känd blott i par tre exemplar (England, Skotland, Sibirien) har stud. Poppius tagit ett exemplar i Kirjavalaks i juli 1895. Membranen, som vanligen blott når till spetsen af abdomen, öfverskjuter denna med halfva sin längd och är i sin helhet blott litet kortare än corium.

6. Orthotylus ericetorum Fall. (= croceus J. Sahlb.). Vid Soc. pro F. et Fl. Fenn. sammanträde d. 4 dec. 1886 förevisade prof. J. Sahlberg en Orthotylus, tagen i 3 exemplar vid Dvorets i Ryska Karelen af hr A. Günther; exemplaren uppfördes under benämningen croceus såsom en ny art, hvilken skulle afvika från $O$. ericetorum genom bjärt gul färg, kortare prothorax och från pannan icke tydligt afsatt tylus. Det typexemplar, jag undersökt, skiljer sig likväl i dessa senare hänseenden icke det ringaste från ericetorum och hemielytra äro äfven tydligt gröna med undantag af spetsen af cuneus, hvilken 
likasom hos ericetorum är gul. Den gröna färgen bleknar och gulnar ofta, om insekten altför länge utsatts för invärkan af cyankalium och härpå torde äfven den gulaktiga färgtonen på hufvud och thorax hos de tre exemplaren från Dvorets bero.

7. Atractotomus mali Mey. Prof. J. Sahlberg har i slutet af juli på äppelträn i Karislojo funnit flere exemplar af denna för vår fauna nya Capsid, som skiljer sig från den hos oss på gran allmänna $A$. magnicornis Fall. genom betydligare storlek, svart cubitalnerv på membranen och äfven hos hanen spolformig andra antennled. I Skandinavien är denna art förut tagen endast af mig på äppelträn invid Stockholm och på Cratregus af kand. Schlick vid Köpenhamn (orätt angifven af mig i Entom. Meddelelser I, B. 3, p. 108, 222 a såsom A. forticornis M. et R.).

8. Aphelocheirus nigrita Horv. och Montandoni Horv. Senaste vårtermin förevisade stud. A. J. Silfvenius inför Soc. pro F. et Fl. Fenn. exemplar af en Aphelocheirus, funna af honom på flodbotten i Nykyrka och Kivinebb socknar och bestämd af d:r Horvath såsom A. nigrita n. sp. Sedermera har d:r Horvaths monografi öfver detta genus publicerats i Termeszet. Füzet. XXII (1899) och beskrifves däri 7 arter, af hvilka 4 europeiska. Af dem tillhöra icke färre än 3 Östersjöbassinen, nämligen $A$. cestivalis Fabr. (= Kervillei Kuhlgatz), funnen vid Schwentine nära Kiel, A. Montandoni n. sp. (= aestivalis $\mathrm{Put}$.), för länge sedan funnen $\mathrm{i}$ ett exemplar af Kolenati vid Peterhof nära Petersburg, samt den nu hos oss funna ofvan nämnda A. nigrita n. sp., af hvilken för öfrigt blott ett exemplar (forma macroptera) är bekant (södra Ungarn). De båda andra äro utbredda öfver en stor del af Europa.

Då jag af prof. J. Sahlberg erfarit att han nyligen i S:t Petersburgs Vetenskaps Akademis zoologiska museum sett exemplar af en Aphelocheirus, funna i Östersjöprovinserna, anhöll jag hos assistenten N. Bianchi om utredning huruvida dessa tillhörde A. nigrita eller $A$. Montandoni. Af hr Bianchis svar framgår att i nämnda museum förvaras två benlösa brachyptera exemplar, funna såsom döda af zoologen vid Vetenskaps Aka- 
demiens Museum Birula vid norra stranden af Finska viken mellan S:t Petersburg och Sestrovetsk, och dessutom en väl bibehållen brachypter 오, tagen af Bianchi i maj 1879 vid södra stranden af Finska viken nära Oranienbaum. Alla dessa tillhöra icke $A$. nigrita, utan $A$. Montandoni, och Bianchi förmodar att till denna art bör hänföras äfven en gul larv, som han funnit under ett trästycke vid den sandiga stranden af floden Luga, 6 verst norr om Tamburg i S:t Petersburgska guvernementet.

Då sålunda äfven denna art blifvit funnen alldeles invid gränsen till vårt faunaområde, är det mycket antagligt att den skall anträffas också inom detta, så snart engång samlares uppmärksamhet tillbörligen riktats på dessa egendomliga kortvingade, larvlika vattenhemipterer. För närmare efterforskning må därför här lämnas en kort öfversikt af de tre arter, hvilka anträffats inom Östersjöbassinen.

A. Montandoni Horv.: kropp ofvan föga konvex, nästan nedtryckt, framtill starkare afsmalnande än baktill, svart eller svartbrun, mer eller mindre gulbrokig, sidoränderna, hufvudet helt och hållet, antenner, rostrum och ben gula; abdomen, metanotum och scutellum tillsamman nästan kortare än abdomens största bredd; honans öfre genital-lameller nästan dubbelt kortare än den mellersta räta delen af sista dorsalsegmentets bakrand.

A. nigrita Horv.: kropp ofvan lindrigt, men tydligt konvex, bredt elliptisk, framåt och bakåt ungefär lika starkt afsmalnande, enfärgadt svart; hufvudet ofvantill stundom i disken mer -eller mindre gulbrunt, undertill, antenner, rostrum och ben lergula; abdomen, metanotum och scutellum tillsamman nästan kortare än abdomens största bredd; honans öfre genitallameller i midten lika långa som hälften af den mellersta räta delen af sista dorsalsegmentets bakrand.

A. æstivalis Fabr., Horv.: kropp ofvan lindrigt, men tydligt konvex, bredt elliptisk, ungefär lika afsmalnande framåt och bakåt, lergul, mer eller mindre gråbrokig, sällan nästan 
helt och hållet gråsvart, men hufvudet alltid rödaktigt eller brunaktigt lergult, enfärgadt; abdomen, metanotum och scutellum tillsamman lika långa som abdomens största bredd; honans öfre genitallameller i midten längre än hälften af den mellersta räta delen af sista dorsalsegmentets bakrand.

Slutligen anser jag mig här böra uttala ett tvifvelsmål huruvida den hos oss funna Aphelocheirus värkligen är identisk med den ifrån södra Ungarn beskrifna nigrita Horv., ehuru Horvath själf anser så vara fallet. Från Ungarn är blott ett långvingadt exemplar kändt, men dettas hufvud är märkbart längre än hos vår art och vingdimensionen brukar icke invärka äfven på hufvudets bygnad. Hufvudet är sålunda lika bildadt hos lång- som hos kortvingade exemplar af A. cestivalis. Frågan kan afgöras först sedan arten är känd i båda formerna, den lång- och den kortvingade. 


\section{$2 \mathrm{BHL}$ Biodiversity Heritage Library}

Favrat, Louis. 1900. "Anteckningar om finska Heteroptera." Meddelanden af Societas pro Fauna et Flora Fennica 26, 124-130.

https://doi.org/10.5962/bhl.part.26727.

View This Item Online: https://www.biodiversitylibrary.org/item/22003

DOI: https://doi.org/10.5962/bhl.part.26727

Permalink: https://www.biodiversitylibrary.org/partpdf/26727.

\section{Holding Institution}

MBLWHOI Library

Sponsored by

MBLWHOI Library

\section{Copyright \& Reuse}

Copyright Status: NOT_IN_COPYRIGHT

This document was created from content at the Biodiversity Heritage Library, the world's largest open access digital library for biodiversity literature and archives. Visit BHL at https://www.biodiversitylibrary.org. 